\title{
Characterization of "Neo-Dermis" Formation Beneath Cultured Human Epidermal Autografts Transplanted on Muscle Fascia
}

\author{
David T. Woodley, M.D., Robert A. Briggaman, M.D., Sandra R. Herzog, B.S., Anthony A. Meyers, M.D., \\ Hugh D. Peterson, D.D.S., M.D., and Edward J. O'Keefe, M.D. \\ Department of Dermatology (DTW, RAB, EJO), University of North Carolina School of Medicine, Chapel Hill, North Carolina, \\ U.S.A. and North Carolina Jaycee Burn Center (SRH, AAM, HDP), University of North Carolina School of Medicine, Chapel Hill, \\ North Carolina, U.S.A.
}

Cultured human keratinocyte autografts were transplanted to burn wounds that had been completely excised down to muscle fascia such that all cutaneous elements were removed from the wounds. Healing autografts were biopsied from days 6-153 in five patients, and the "neo-dermis" beneath the autografts was examined by immunofluorescent staining using antibody probes to connective tissue molecules, by histochemical staining for elastin fibers, and by electron microscopy. We found that the neo-dermis contained most of the major connective tissue elements early in the post-transplantation period. However, regardless of the time examined, there was a paucity of elastin fibers and poor organization of linkin (microthread-like fibers) in the neo-dermis beneath autografts. The perturbations of these connective tissue components in the neo-dermis may play a role in the poor recoil and elastic properties of burn wounds treated with autografts. J. Invest Dermatol 95:20-26, 1990
A utologous, cultured, human keratinocyte sheets have been used to permanently cover large burn wounds $[1-13]$. We recently reported seven burn patients in which cultured human keratinocyte sheets were transplanted onto muscle fascia $[12,13]$. In these patients, the wound bed was completely excised down to muscle fascia immediately before the cultured keratinocyte sheets were placed on the wound. This assured that the origin of the epidermis in the healing wound was from the cultured grafts because all of the skin appendages in the deep dermis and subcutaneous fat were removed prior to placing the transplants. One remarkable feature of cultured autografts transplanted onto muscle fascia is that a neo-dermis rapidly forms between the cultured autografts and the muscle fascia. In this report, we characterize this neo-dermis using antibodies to various connective tissue molecules, histochemical stains, and electron microscopy.

\section{METHODS}

The clinical features of the original burn victims and the methods by which they received cultured epidermal autografts transplanted to their burn wounds after the wounds were excised to muscle fascia

Manuscript received June 5, 1989; accepted for publication March 6 . 1990.

Reprint Requests: Dr. David T. Woodley, Department of Dermatology, Stanford University School of Medicine, Edwards Building, Room R-144, Stanford, California 94305.

These studies were supported by grants AR33625, AR10546, AR25871, and AR36497 from the National Institutes of Health.

Dr. Woodley is a recipient of Research Career Development Award AR01540.

Abbreviation:

PBS: phosphate-buffered saline have been detailed previously $[12,13]$. In essence, we followed the culture and grafting techniques of Gallico et al [1]. All of the wound bed recipient sites were excised down to muscle fascia, which removed all of the cutaneous elements from the bed. The cultured epidermal sheets were removed from the petri dishes with Dispase and placed directly on the prepared muscle fascia bed of burn wounds. The cultured keratinocyte sheets, apposed to muscle fascia, were covered with petrolatum gauze and kept moist with saline soaks. Punch biopsies without local anesthesia (none was needed to relive pain) were performed between post-transplantation days 6 and 153 on five patients for light, immunofluorescent, and electron microscopy.

Immunofluorescence Biopsies for immunofluorescence were immediately oriented in OCT cryogel (Napersville, IL) and frozen in liquid nitrogen. Sections $8 \mu$ thick were cut with a Reichert Jung cryostat cryotome. In order to determine the presence or absence of known major dermal connective-tissue components, the sections were stained by indirect immunofluorescent methods $[12,14,15]$ with the following antibodies: i) affinity-purified, anti-human type I collagen IgG made in sheep [16] diluted 1:10 in phosphate-buffered saline (PBS), ii) anti-human type III collagen (Chemicon International, El Segundo, CA) diluted 1:10 in PBS, iii) affinity-purified, anti-type VI collagen made in rabbits (gift from Dr. Edward Cleary, University of Adelaide, South Australia) diluted 1:10 in PBS, iv) affinity-purified, anti-fibronectin rabbit IgG $[17,18]$ diluted $1: 50$ in PBS, v) affinity-purified, anti-human elastin and tropoelastin rabbit IgG antibodies [19] (gift from Dr. Robert Mecham, Washington University School of Medicine, Saint Louis, MO) and vi) anti-linkin, murine monoclonal antibody which labels $80-\mathrm{kD}$ and $73-\mathrm{kD}$ proteins in dermal extracts of skin that are associated with microthread-like filaments in the papillary dermis of human skin [20].

In order to determine the presence of neovascularization, blood vessels in the substrates were labeled by staining the sections with 
anti-laminin [16] antibodies diluted 1:40 and anti-type IV collagen antibodies [16] diluted 1:10 which are known to stain basement membranes around dermal blood vessels [21].

In order to examine the presence or absence of endothelial cells, the substrates were labeled with antibodies to factor 8 (Synbiotics Corporation, San Diego, CA) diluted 1:10.

All second-step, fluoroscein isothiocyanate-labeled conjugates, appropriate for the IgG species of the primary antibody, were obtained from Cappel-Organon Teknika, West Chester, PA, and used at a dilution of $1: 40$.

In order to determine working dilutions for the above antibodies, normal human skin substrate obtained from two normal volunteers was labeled with serial dilutions of the above antibodies and the extinction titer for each antibody determined. Working dilutions on the experimental substrates were several times more concentrated than the extinction titer on normal human skin. When antibodies were made in a given animal (e.g., rabbit), the control for "background" staining consisted of identical dilutions of serum from a like, non-immunized, normal animal.

Histochemical Staining In order to examine collagen bundles, elastic fibers, and cellular elements within the neo-dermis, $8-\mu$ frozen sections were fixed for $1 \mathrm{~min}$ with $10 \%$ formaldehyde, stained with Verhoeff-van Gieson reagents, dehydrated in $95 \%$ and $100 \%$ alcohol, mounted in permount, and examined and photographed on a Leitz microscope. The Verhoeff-van Gieson procedure stains dermal elastin dark blue to black, dermal collagen deep pink or red, cellular elements light gray, and other tissue elements yellow [22].

In order to quantitate elastic fibers in tissue, specimens were stained with the Verhoeff-van Gieson stain and five or more random fields under oil immersion, high-power $(\times 420)$ microscopy were photographed in a blinded fashion. Images were then digitized on a Summa graphics tablet linked to an IMB-XT computer equipped with an IBM program designed to measure, list, sum, and average the lengths and areas of free-formed objects. With this computer-assisted image analysis, the total and mean lengths of elastic fibers in each high-powered field were determined.

Electron Microscopy Biopsies from healing cultured epidermal autografts covering burn wounds excised to muscle fascia were obtained between days 6 and 153 and fixed overnight in half-strength Karnovsky's fixative at $4^{\circ} \mathrm{C}$, postfixed in osmium tetroxide, embedded in epoxy resin, and stained with uranyl acetate and lead citrate. The specimens were viewed and photographed with a JEM $100 \mathrm{~B}$ electron microscope.

\section{RESULTS}

Light and electron microscopy and immunofluorescent staining of the specimens with specific antibodies showed that the new tissue ("neo-dermis") formed between the muscle fascia bed and the cultured epidermal autografts contained many of the major connective tissue components that are present in authentic, unwounded, normal, adult, human skin dermis (Figs 1,2, and 8). The major collagens, types I, III, and VI, were distributed diffusely throughout the neo-dermis (Fig 1) in a pattern indistinguishable from normal control skin. Fibronectin, a major dermal and plasma glycoprotein, was localized diffusely throughout the neo-dermis below the autografts similar to the pattern seen in normal, unwounded skin (Fig 2). The diffuse patterns of staining the neo-dermis beneath the cultured autografts with these four antibodies remained constant throughout the study period in all of the patients.

To determine whether or not the neo-dermis beneath cultured autografts was vascularized, the specimens were stained with antibodies to laminin and type IV collagen, which label basementmembrane structures around dermal blood vessels as well as basement membrane in the dermal-epidermal junction. The neo-dermis was found to be highly vascularized in the earliest obtainable specimens (post-transplantation day 6-11) in all patients and remained so throughout the study period (Fig 3). Although not quantitated systematically, it appeared that the vascularization of the neo-
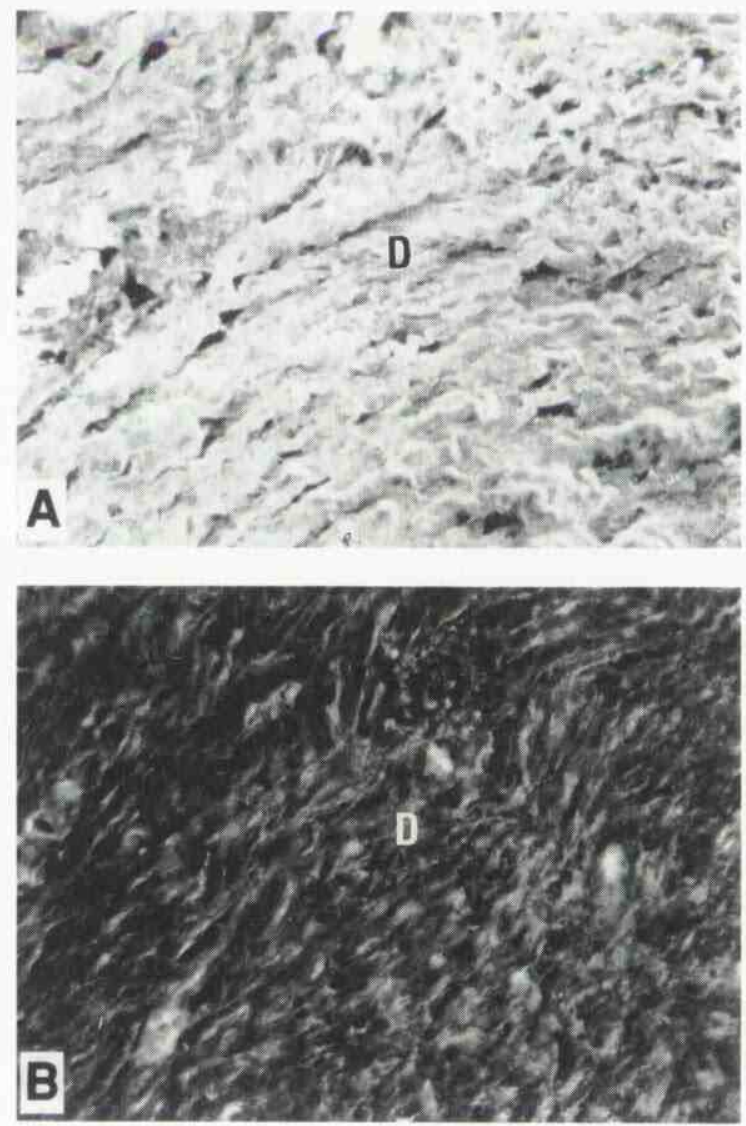

Figure 1. Immunofluorescent staining of the neodermis beneath cultured autografts at 90 days post-transplantation with sheep antibodies to human type I collagen (A), or normal sheep serum diluted 1:10 (B). (Magnification $\times 384$ in $A$ and $B$.) (D, neo-dermis). Antibodies to type III and type VI collagens produced the same diffuse staining of the neo-dermis as antibodies to type I collagen (not shown).

dermis was more exuberant at early time points compared with those specimens taken after day 40 post-transplantation.

To examine the microthread-like fibrils that are localized within the basement-membrane zone and papillary dermis of normal human skin, specimens from normal human skin and neo-dermis beneath autografts were stained with an anti-linkin, a murine monoclonal antibody. This antibody specifically reacts with $80-\mathrm{kD}$ and $73-\mathrm{kD}$ proteins extracted from microthread-like fibrils in human skin [20]. Normal human skin labeled with this antibody showed an intense, tightly organized fluorescent band at the dermal-epidermal junction and high papillary dermis (Fig 4). In contrast, in all of the autograft specimens, regardless of the day obtained after transplantation, the antibody labeled the neo-dermis diffusely throughout the specimen with low to moderate intensity and did not exhibit any preferential localization to the dermal-epidermal junction (Fig 4). This diffuse pattern of linkin in the neo-dermis extended throughout the dermis down to the apposed muscle fascia (Fig $4 F$ ) and remained diffuse throughout the study period.

In contrast to the major collagens and fibronectin, elastin in the neo-dermis was markedly decreased at all time points in all patients (Figs 5 -7). The long dark elastic fibers seen in unwounded, normal control skin by histochemical staining (either from the patient or normal volunteers) were markedly diminished in the neo-dermis specimens even at five months post-transplantation (Fig 5). At early time points such as day 11 after transplantation, the developing neo-dermis consists of irregular, small, wispy connective tissue fibers when compared to normal dermis or neo-dermis at later time points (compare Fig $5 B$ with $5 A, C$ and $D$ ). Immunofluorescent staining of normal unwounded skin and autograft neo-dermis with 

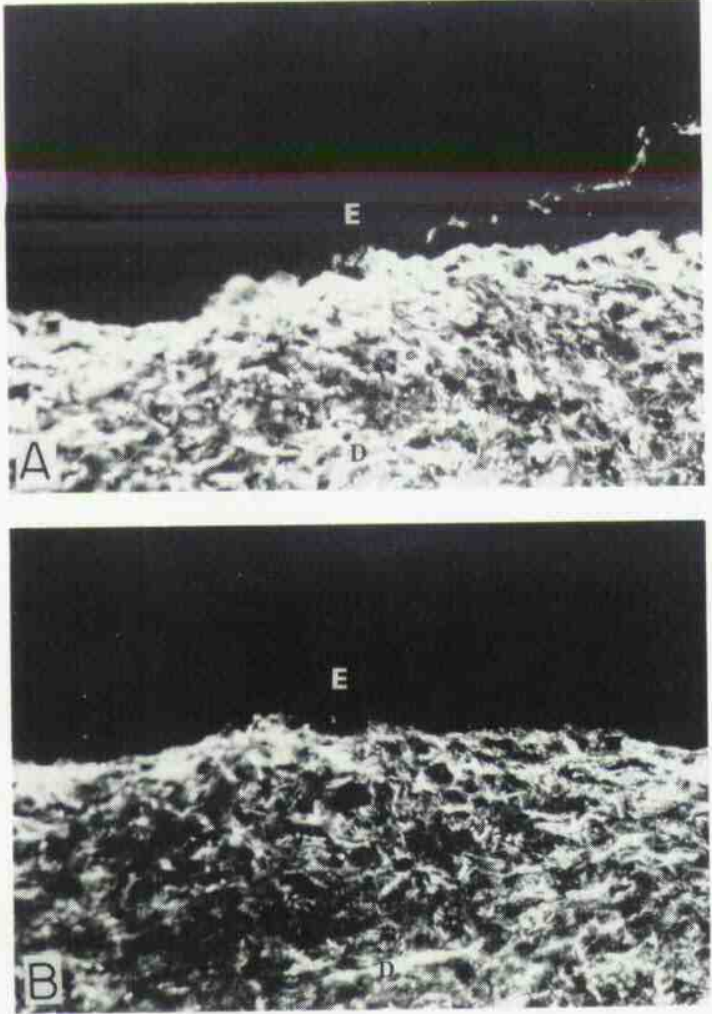

Figure 2. Immunofluorescent staining of neo-dermis beneath cultured autografts at post-transplantation days $23(A)$ and $57(B)$ with affinity-purified antibodies to fibronectin diluted 1:50 (magnification $\times 300$; E, epidermis; $\mathrm{D}$, neo-dermis).
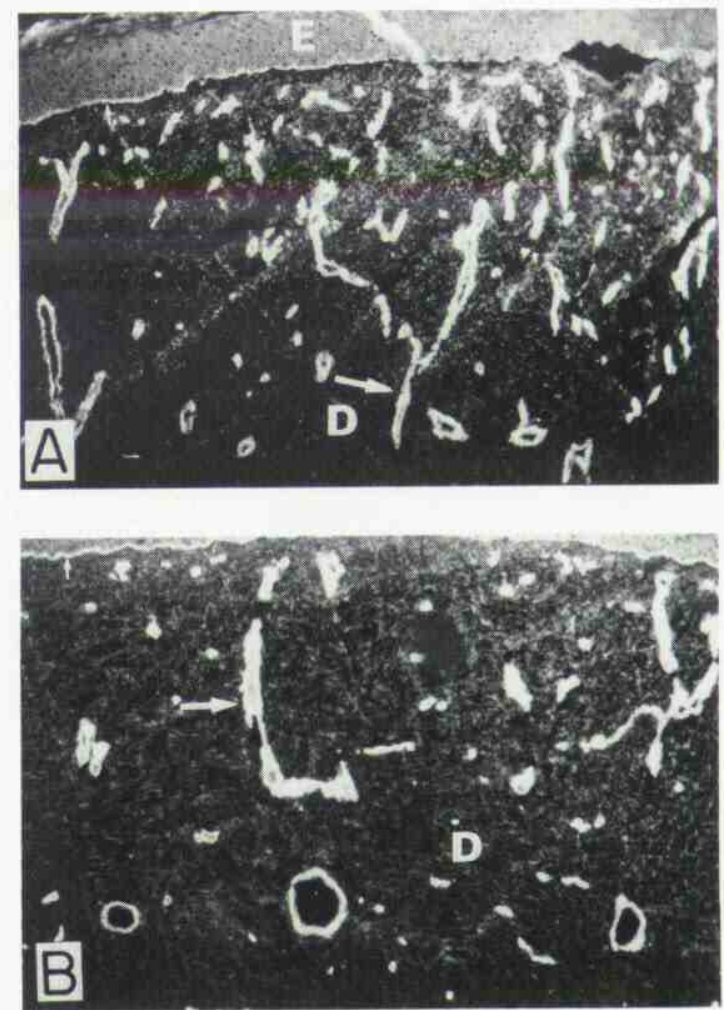

Figure 3. Immunofluorescent staining of neo-dermis beneath cultured autografts at post-transplantation days $11(A)$ and $90(B)$. Although the staining of dermal blood vessels appears very similar in the photographs, antibodies to type IV collagen were used in $A$ and antibodies to laminin were used in $B$ (magnification $\times 180$; E, epidermis; D, neo-dermis).
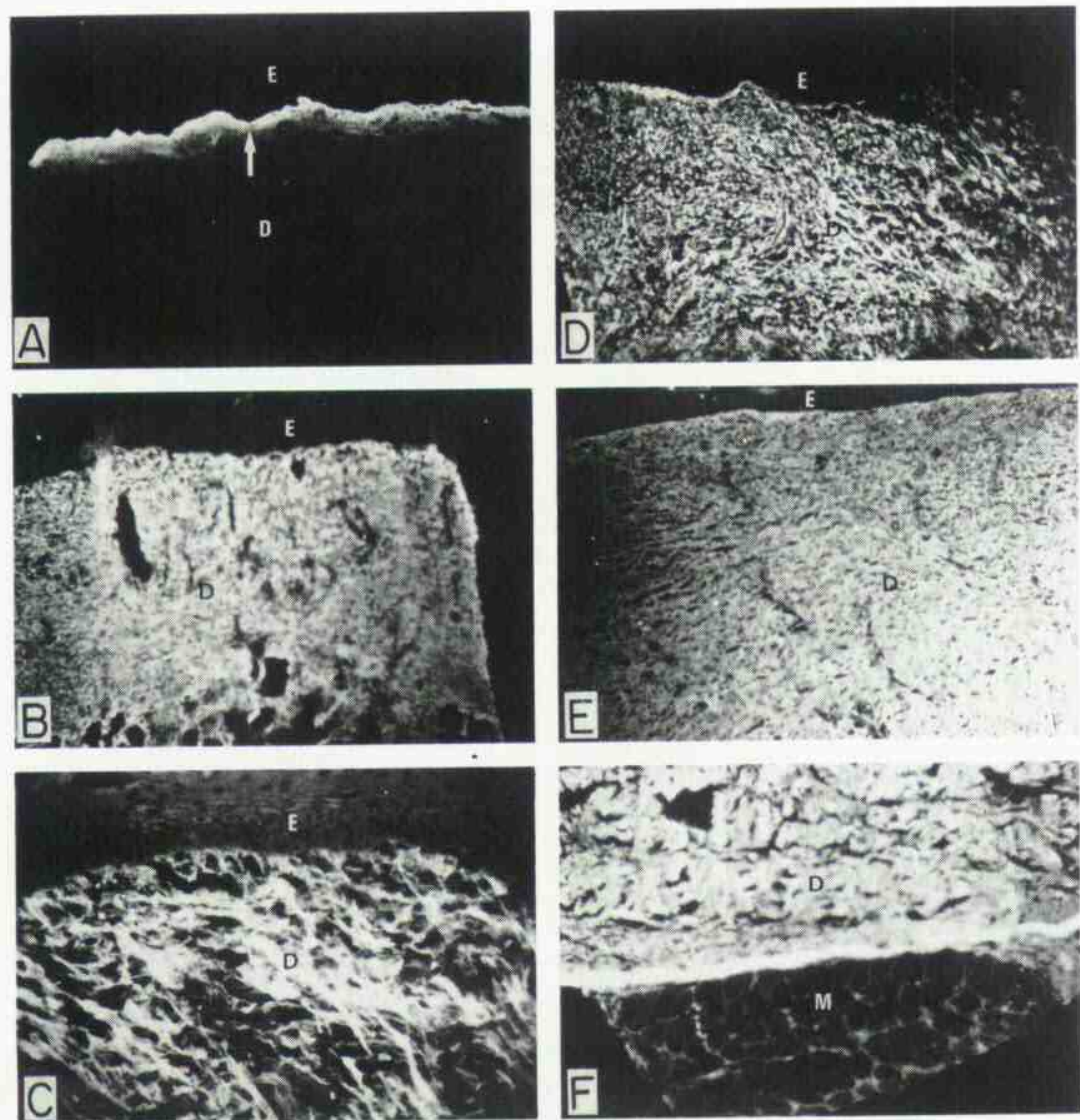

Figure 4. Normal human skin $(A)$ or neo-dermis beneath cultured autografts $(B-F)$ stained with antibodies to linkin [20]. Specimens are shown at low power (magnification $\times 72$ ) from post-transplantation days 11 (D), $30(B)$, and $153(E)$. Higher power (magnification $\times 210$ ) photographs of the top (C) and bottom (F) of a day-21 specimen are shown. Note that in normal unwounded skin $(A)$, linkin is confined to the papillary dermis (arrow), whereas in specimens of neo-dermis beneath autografts, linkin is expressed diffusely throughout the neodermis with no preferential localization to the papillary dermis. This diffuse pattern of linkin is throughout the neo-dermis: from the papillary dermis $(C)$ down to the inferior pole of the dermis $(F)$ apposed to muscle (M) fascia. (E, epidermis; D, dermis or neodermis.) 

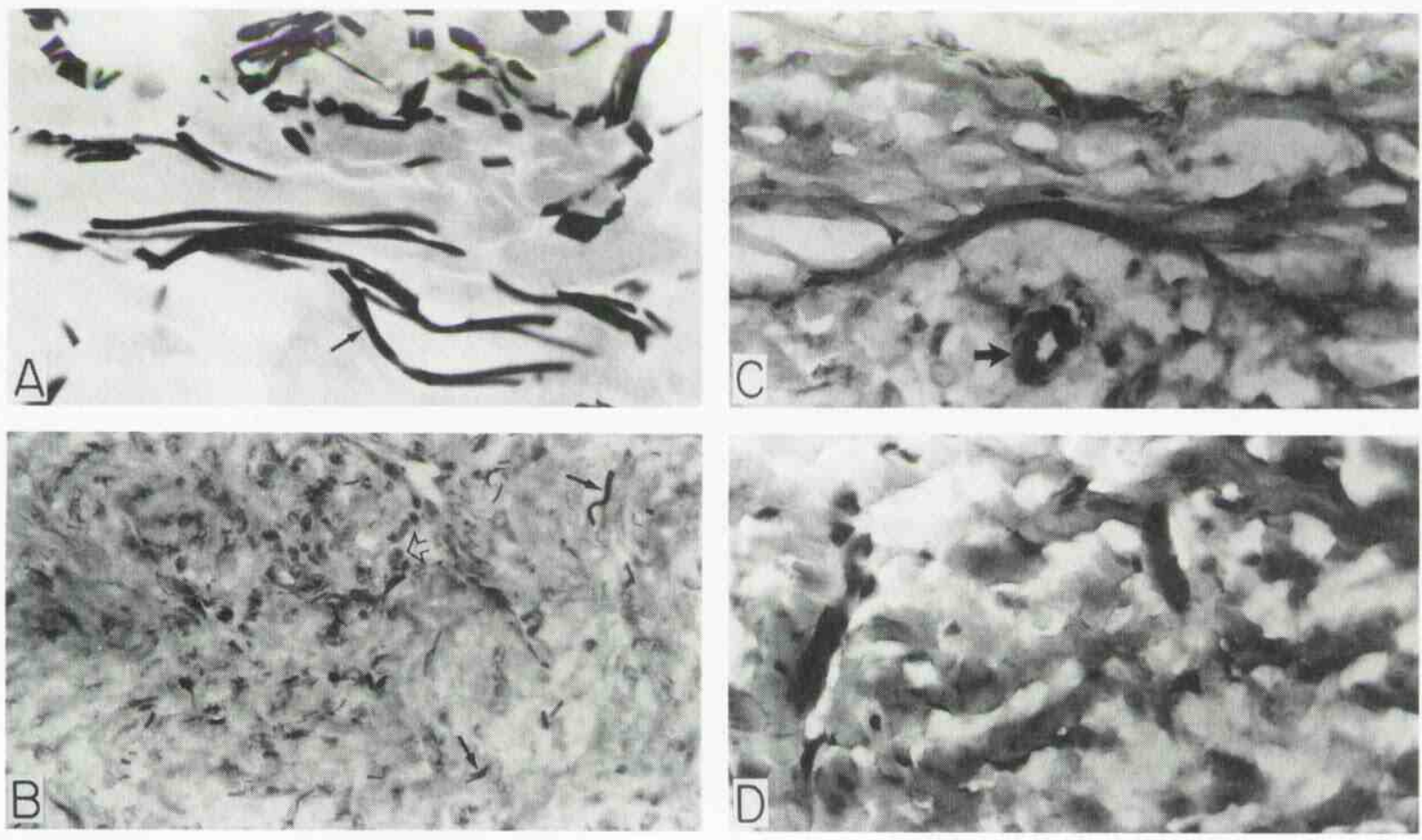

Figure 5. Histochemical staining for elastin by the Verhoeff-van Gieson procedure of normal human skin $(A)$ and neo-dermis beneath autografts ( $B-D)$ taken at post-transplantation days 11 (B), 57 (C), and 153 (D). The open arrow in B points to one of many round inflammatory cells. In $C$, cells forming a round vascular channel are identified (arrow) (magnification $\times 420$ ). The small solid arrows point to elastic fibers.

antibodies to elastin or tropoelastin was in total accordance with staining the tissue by Verhoeff-van Gieson reagents. Again, there were markedly diminished elastin fibers in the upper and middle levels of the neo-dermis. The elastin fibers that were labeled by either immunofluorescent procedures or histochemical staining were attenuated in width and length and were localized predomi- nantly at the base of the specimens where the neo-dermis was apposed to muscle fascia (Fig 6). In some specimens, it appeared as if the stainable elastin fibers were forming a linear condensation that was streaming into the neo-dermis from the base or side. Elastic fibers are known to have some degree of "autofluorescent" properties. In order to assess "background" fluorescence, skin sections
Figure 6. Immunofluorescent staining of normal, unwounded control skin $(A$, top; $B$, base) and neo-dermis beneath cultured autografts $(D$, top; $E$, base; day 153 post-transplantation) with antibodies to human aortic elastin. Control normal skin is stained with rabbit anti-laminin antibodies $(C)$ and normal rabbit serum diluted $1: 10(F)$. Note the lack of elastic fiber staining in top and mid-dermis of the autograft (D) while some small elastic fibers are seen at the base of the specimen $(E)$ (magnification $\times 210$ ).
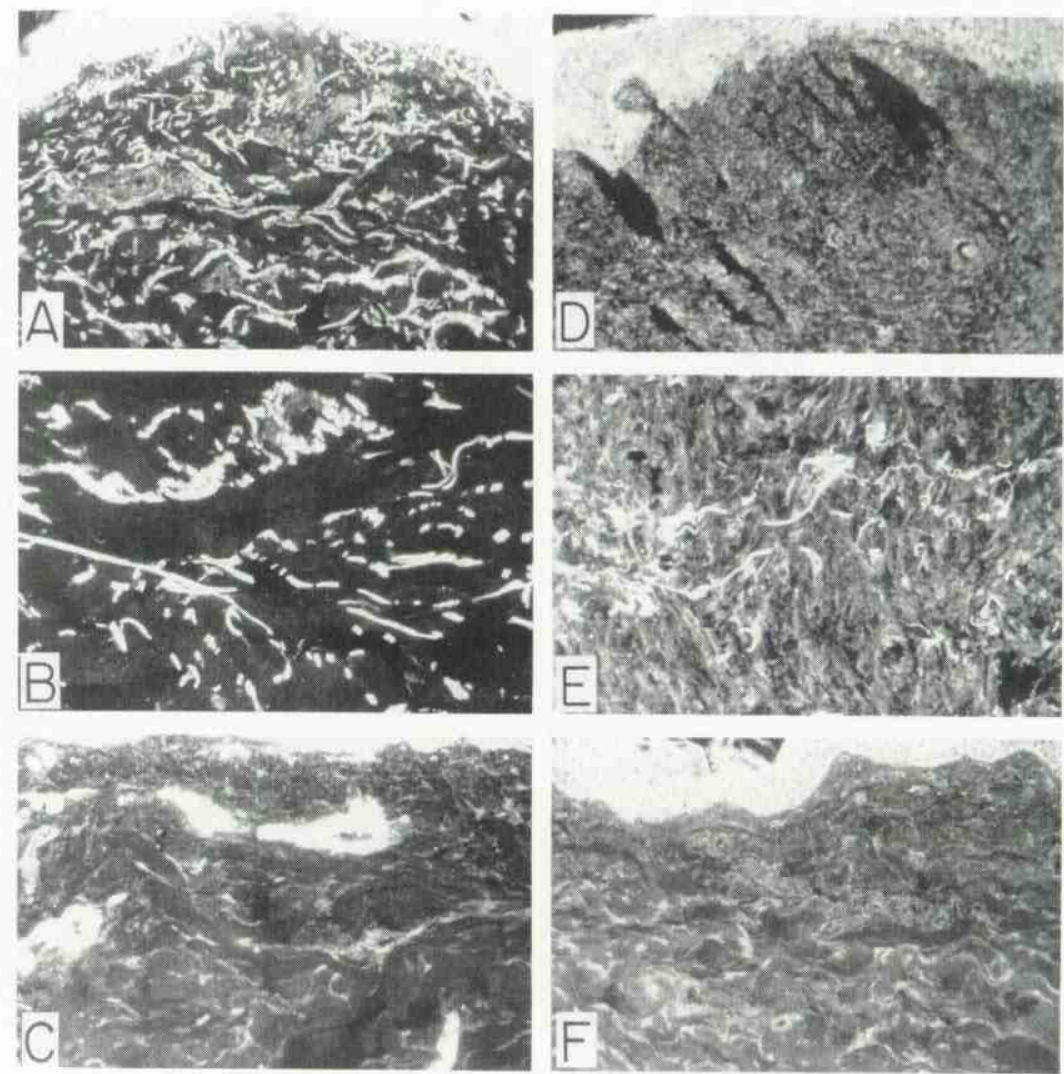
were stained with rabbit antiserum to laminin and normal rabbit serum. As expected, the antiserum to laminin-labeled dermal blood vessels (Fig 6C) and the normal rabbit serum gave a low-moderate level of background dermal staining (Fig 6F). However, the specific labeling of elastin with the anti-elastin or anti-tropoelastin antibodies was clearly discernable due to the size and intensity of the labeled fibers. (Compare Fig $6 A$ and $B$ with Fig $6 C$ and $F$.)

The elastic fibers in the neo-dermis beneath cultured autografts were decreased, and the mean length of the elastic fibers in neodermis was markedly shorter than those in normal control dermis (Figs 5-7). In order to quantitate this reduction, the lengths of all elastic fibers in random, non-overlapping fields of neo-dermis or dermis were determined by computer-assisted morphometry and summed. As shown in Fig $7 A$, the total length of summed elastic fibers per field is reduced markedly in the neo-dermis compared with the dermis of normal skin. Figure $7 B$ shows that the mean lengths of the elastic fibers in specimens of neo-dermis were decreased and more variable than those in normal control dermis.

The Verhoeff-van Gieson staining of the autograft specimens also showed that the neo-dermis was very cellular, particularly at early time points after transplantation. Both spindle-shaped cells and round or polygonal cells, some forming vascular-like structures, could be visualized (Fig $5 C$ ). In some specimens, cells forming vascular structures were seen and stained positive with anti-factor VIII antibodies consistent with endothelial cells.

Electron Microscopy Electron microscopy of the autograft specimens showed that the neo-dermis, like unwounded normal skin, contained well-formed collagen fibers that exhibited a characteristic 64-nm periodicity that is due to the alignment of these fibers in a "one-quarter stagger" arrangement [23]. In early specimens (days 6-50), considerable electron-dense amorphous material in the specimens was visualized that appeared to be between collagen bundles and microfibrils (Fig $8 A$ ). Fibroblasts with abundant rough endoplasmic reticulum were seen next to layers of collagen fibers and microfibrils (Fig $8 A$ ). At later time points (days $50-153$ ), the collagen bundles appeared increased in number and more compact. The amount of electron-dense amorphous material appeared relatively less, and microfibrils were organized into bundles (Fig $8 B$ ). In support of the identification of the latter as elastic microfibrils are their regular beaded periodicity on longitudinal section (Fig 8A) and their diameter of approximately $9 \mathrm{~nm}$ and hollow profile on cross-section (Fig 8B) [24].

\section{DISCUSSION}

From the observations in this study, it can be said that the neodermis which forms within 10 days when human, cultured keratinocyte sheets are transplanted onto muscle fascia contains most of the essential connective tissue and cellular elements that are present in authentic unwounded dermis in normal skin. There were, however, two notable differences between the neo-dermis beneath the autografts and authentic human dermis. First, there was a marked paucity of elastic fibers within the neo-dermis compared with the dermis of normal skin. The elastic fibers that were present in the neo-dermis appeared attenuated and disorganized. Elastic fibers are known to be composed of amorphous, insoluble elastin surrounding a scaffold of microfibril bundles. Our antibodies and the Verhoeffvan Gieson stain label the amorphous elastin. Parallel analyses of specimens examined by histochemical staining for elastin and by electron microscopy showed that the neo-dermis had both interstitial collagen bundles and microfibril bundles early in the post-transplantation period. We were surprised to find microfibril bundles in the autograft specimen vis á vis a dramatic decrease in stainable elastin fibers by classical histochemical methods. Considering the histochemical staining and electron microscopy together, it appears that the neo-dermis contains the microfibril component of the elastic fiber but lacks the amorphous elastin component. Moreover, the elastic fibers that were present had a preferential localization at the base of the specimens, that is, the surface most closely apposed to the muscle fascia on which the autografts were transplanted.

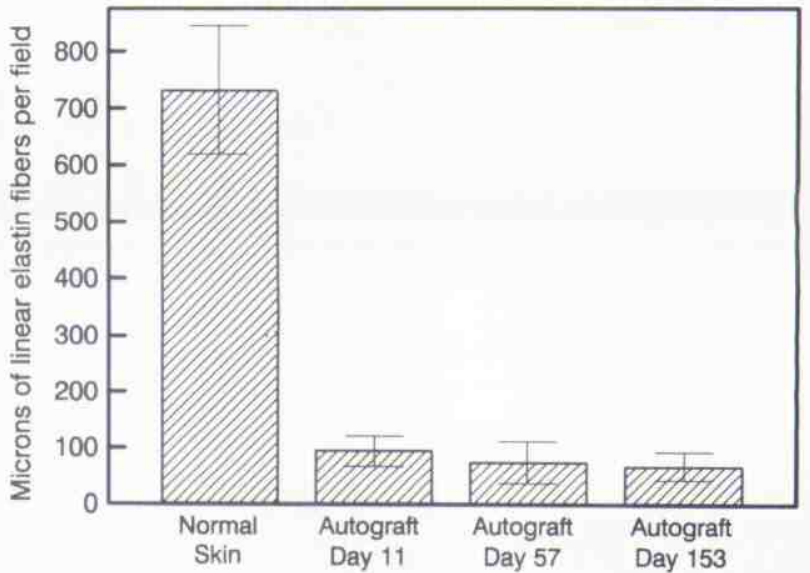

A.

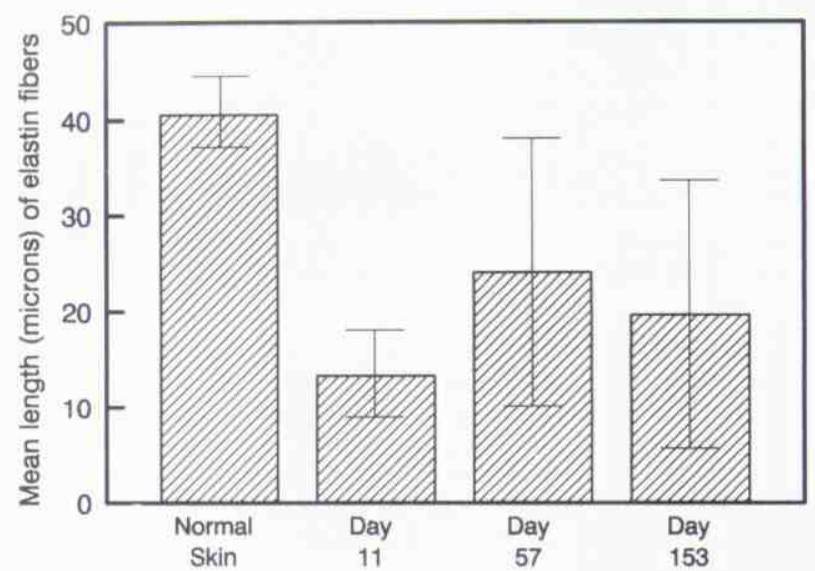

B.

Figure 7. Quantitation of stainable elastin fibers per random high-powered field of normal skin and neo-dermis beneath autografts by computer-assisted image analysis. Bar, mean value of five or more random, high-powered fields from each specimen. Error bars, SEM.

A second major difference in the neo-dermis was the abnormal staining with anti-linkin antibody, which labels microthread-like fibrils in the papillary dermis of normal skin. This antibody produced a diffuse, attenuated fluorescent stain in all of the autograft specimens and never exhibited the tightly organized, intense staining of the dermal-epidermal junction that is seen in normal skin. Clinically, healed autograft wounds feel leathery and have less recoil than unwounded skin. Moreover, some autograft patients have skin fragility and poor epidermal-dermal adherence when tested with a suction blistering device [12]. It is conceivable that the paucity of elastic fibers and the poorly organized microthread-like fibrils at the dermal-epidermal junction of healed autografts could account for some of these clinical changes. However, except for the study of elastic fibers, this study is completely qualitative in nature and only addresses the presence or absence of these elements and their distribution within the neo-dermis without assessing the function or the quantity of these dermal components.

Because our antibody probes presumably only bind to their respective binding sites on a given component, it is conceivable that some of the connective tissue elements are only partially reconstituted between the autograft and the muscle fascia. Nevertheless, it is remarkable that most of the essential elements of dermis are present beneath the autografts within 6 to $10 \mathrm{~d}$. Some of these dermal components may be reconstituted earlier, but we found that we would perturb the culture autograft and possibly damage it if we attempted to unbandage the wound and obtain biopsies any earlier. 
Figure 8. Electron microscopy of neo-dermis beneath autografts at post-transplantation days $11(A)$ and $153(B)$. The long-tailed arrows point to collagen bundles with a characteristic $64-\mathrm{nm}$ periodicity. The short-tailed arrows point to microfibril bundles with their regular beaded periodicity $(A)$ and diameter of approximately $9 \mathrm{~nm}$ and hollow profile on cross-section (B). (FB, fibroblast. Scale bars, $1 \mu$ ).
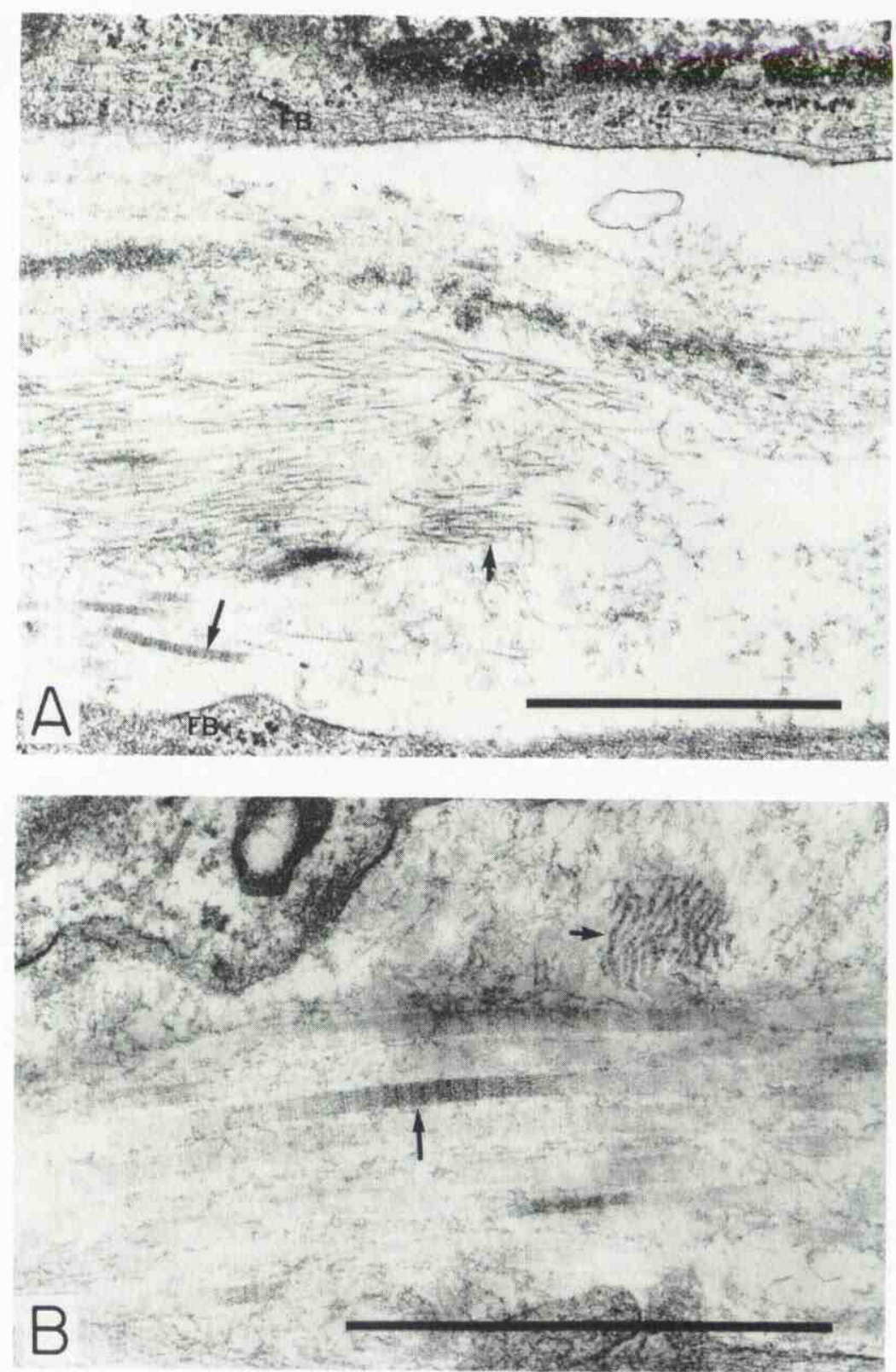

It should be noted also that while there may or may not be complete reconstitution of some dermal connective tissue elements within the neo-dermis beneath autografts, there are many structures that are formed and, when viewed with the electron microscope, appear to approach structures observed in normal, unwounded dermis.

These observations raise several important questions. From where do these components come? Are these elements mobilized from tissues juxtaposed to the graft sites or are they induced locally by the autografts. The studies here do not answer these questions, but it appears that the technique of excising away all cutaneous tissue from burn wound beds and covering them with cultured autografts not only provides the patient with a permanent cover for his or her burns but also offers a unique opportunity to study a model of epidermal-mesenchymal interactions in which the major components of human dermis are rapidly reconstituted.

Addendum: Since the preparation of this manuscript, an article by Compton et al (Lab Invest 60:600-612) described similar studies which were performed on 21 burned children who were followed for as long as five years after transplantation in some cases. Our short-term studies are largely in accordance with Compton et al except that they found considerable "normalization" of elastic fibers in the neodermis four or five years after culture autograft transplants were in place.

The authors are grateful to Ms. Donna Foushee for the preparation of this manuscript.

\section{REFERENCES}

1. Gallico CG, O'Connor NE, Compton CC, Kehinde O, Green H: Permanent coverage of large burn wounds with autologous cultured human epithelium. N Engl J Med 311:448-451, 1984

2. Cuono C, Langdon R, McGuire J: Use of cultured autografts and dermal allografts as skin replacement after burn injury. Lancet I: $1123-1124,1986$

3. Cuono CB, Langdon R, Birchall N, Bartelbort S, McGuire J: Composite autologous-allogeneic skin replacement: development and clinical application. Plast Reconstr Surg 80:626-635, 1987

4. O'Connor NE, Mulliken JB, Banks-Schlegel S, Kehinde O, Green H: Grafting of burns with cultured epithelium prepared from autologous epidermal cells. Lancet I:75-78, 1981 
5. Teepe RGC, Ponce M, Kreis RW, Hermans RP: Improved grafting method for treatment of burns with autologous cultured human epithelium. Lancet I:385, 1986

6. Kumagai N, Nishina H, Tanabe H, Hosaka T, Ishida H, Ogino Y: Clinical application of autologous cultured epithelia for the treatment of burn wounds and burn scars. Plast Reconstr Surg 82:99108,1988

7. Faure M, Maudit G, Schmitt O, Kanitakis J, Demidem A, Thivolet J: Growth and differentiation of human epidermal cultures used as auto- and allografts. Br J Dermatol 116:161 -170, 1987

8. Hefton JM, Caldwell D, Biozes DG: Grafting of skin ulcers with cultured autologous epidermal cells. J Am Acad Dermatol 14:399 405,1986

9. Eisinger M, Monden M, Raff JH: Wound coverage by a sheet of epidermal cells grown in vitro from dispersed single cell preparations. Surgery 88:207-293, 1980

10. Gallico GG, O'Connor NE: Cultured epithelium as a skin substitute. Clin Plast Surg 12:149-157, 1985

11. Green H, Kehinde O, Thomas J: Growth of cultured human epidermal cells into multiple epithelia suitable for grafting. Proc Natl Acad Sci USA 76:5665-5668, 1979

12. Woodley DT, Peterson HD, Herzog SR, Stricklin GP, Burgeson RE, Briggaman RA, Cronce DJ, O'Keefe EJ: Burn wounds resurfaced by cultured epidermal autografts show abnormal reconstitution of anchoring fibrils. JAMA 259:2566-2571, 1988

13. Herzog SR, Meyer A, Woodley DT, Peterson HD: Wound coverage with cultured autologous keratinocytes: use after burn wound excision, including biopsy followup. J Trauma 28:195-198, 1988

14. Beutner EH, Nisengard RJ, Kumar V: Defined immunofluorescence: Basic concepts and their application to clinical immunodermatology. In: Beutner EH, Chorzelski TP, Bean SF (eds.). Immunopathology of the Skin, Second Edition, New York, John Wiley and Sons Inc., pp 29-76, 1979
15. Woodley DT, Sauder D, Talley MJ, Grotendorst G, Silver M: Localization of basement membrane components after dermal-epidermal junction separation. J Invest Dermatol 81:149-153, 1983

16. Woodley DT, Rao CN, Hassell JR, Liotta LA, Martin GR, Kleinman HK: Interactions of basement membrane components. Biochim Biophys Acta 761:278-283, 1983

17. O'Keefe EJ, Payne Jr RE, Russell N, Woodley DT: Spreading and enhanced motility of human keratinocytes of fibronectin. J Invest Dermatol 85:125-130, 1985

18. O'Keefe EJ, Woodley DT, Castillo G, Russell N, Payne RE: Production of soluble and cell associated fibronectin by cultured keratinocytes. J Invest Dermatol 82:150-155, 1984

19. Mecham RP, Lange G: Antibodies to insoluble and solubilized elastin. In: Cunningham LW, Frederiksen DW (eds.). Methods in Enzymology, Volume 82. Academic Press, New York, pp 744-758, 1982

20. Yoshiiki T, Briggaman RA, Woodley DT, Gammon WR, Cronce DJ: Identification and partial characterization of a microthread-like filamentous network beneath the human skin basement membrane zone. J Invest Dermatol 90:620, 1988

21. Stanley JR, Woodley DT, Katz SI, Martin GR: The structure and function of basement membrane. J Invest Dermatol 79 (suppl):6972,1982

22. Lever WF, Schaumberg-Lever G: Histopathology of the Skin, Sixth Edition, J. B. Lippincott Co, New York, pp 42-46, 1983

23. Piez KA: Primary structure of collagen. In: Ramachandran GN, Reddi AH (eds.). Biochemistry of Collagen, Plenum Press, New York, pp $1-4,1976$

24. Briggaman RA: The epidermal-dermal junction and genetic disorders of this area. In: Goldsmith LA (ed.). Biochemistry and Physiology of the Skin. Oxford University Press, Oxford, pp 1001-1024, 1983

\section{COURSE ANNOUNCEMENT}

The course "Dermatology Update and All That Jazz" will be held April 24-26, 1991 in New Orleans, Louisiana, sponsored by Tulane University Medical Center, Office of Continuing Education. The coordinator is Larry E. Millikan, M.D. Credit: 17 hours, category 1. Cost: \$250. Specialty: dermatology. Contact the Office of Continuing Education, (504) 588-5466. 